\title{
ANALISA TINGKAT KEBISINGAN PADA MESIN STRIP OBAT
}

\author{
Noise Level Analysis in Drug Strip Machines \\ Dimas Suryo Ajitomo ${ }^{1 *}$ \\ ${ }^{1}$ PT. Medifarma Laboratories, Jl. Raya Bogor KM.33, Indonesia
}

Informasi artikel

Diterima: $14 / 05 / 2019$

Direvisi : 20/05/2019 Disetujui: 22/05/2019

\begin{abstract}
Abstrak
Obat-obatan dalam kehidupan sehari-hari merupakan kebutuhan yang tidak dapat dianggap sebagai kebutuhan tersier dikarenakan dalam situasi dan kondisi tertentu obat dapat menjadi kebutuhan yang sangat penting. Perusahaan farmasi bersaing untuk menghasilkan produk dengan kualitas yang optimal dan memasarkan produknya yang meliputi obat bebas (OTC, Over The Counter) dan obat resep (ETC, Ethical) untuk memenuhi permintaan konsumen di pasar lokal maupun internasional. Industri farmasi memiliki beberapa tahapan proses, yaitu proses penyimpanan material bahan, produksi, sampai pengemasan. Pada proses pengemasan yang terkait didalamnya adalah proses penyetripan kaplet yang dilakukan menggunakan mesin yang sesuai dengan jenis kapletnya. Walapun demikian, masalahmasalah pada mesin yang menghambat kelancaran proses produksi akan terjadi. Mencari solusi yang tepat untuk masalah yang timbul dan menghambat kelancaran proses produksi mampu dikurangi, dengan tujuan meningkatkan produktifitas mesin, mengurangi reject pada mesin stripping, meningkatkan tingkat keselamatan kerja operator, dan meningkatkan efisiensi dalam proses produksi.
\end{abstract}

Kata Kunci: Obat, industri, produksi, pengemasan, mesin strip.

\begin{abstract}
Drugs in daily life are needs that cannot be considered tertiary needs because in certain situations or conditions drugs can be very important needs. Pharmaceutical companies compete to produce optimal quality products and market their products including OTC, Over The Counter and prescription drugs (ETC, Ethical) to meet consumer demand in local and international markets. The pharmaceutical industry has several stages of the process, namely the process of storing material materials, production, and packaging. In the packaging process that is related in it is the process of sorting caplets which are carried out using machines that are in accordance with the type of caplet. Even so, problems on the engine that hamper the smooth production process will occur. Finding the right solution for problems that arise and inhibiting the smooth production process can be reduced, with the aim of increasing machine productivity, reducing reject on stripping machines, increasing the level of operator safety, and increasing efficiency in the production process.
\end{abstract}

Keywords: Medicine, industry, production, packaging, strip machinery.

*Penulis Korespondensi : Handphone: 08179474352

email : suryodimas@gmail.com 


\section{PENDAHULUAN}

Kebutuhan akan obat-obatan dalam kehidupan kita sehari-hari merupakan kebutuhan yang tidak dapat dianggap sebagai kebutuhan tersier. Hal ini dikarenakan dalam situasi dan kondisi tertentu kebutuhan akan obat-obatan dapat menjadi suatu kebutuhan yang amat penting didalam kehidupan seharihari. Perusahaan-perusahaaan farmasi bersaing untuk menghasilkan dan memasarkan produknya yang meliputi obat bebas (OTC, Over The Counter) dan obat resep (ETC, Ethical) untuk pemenuhan kebutuhan konsumen di pasar lokal maupun pasar internasional. Dengan membuat produk-produk yang dapat dikenal di seluruh lapisan masyarakat sebagai produk yang inovatif dengan mutu dan harga terjangkau.

Dalam industri farmasi terdapat beberapa tahapan proses, mulai dari proses penyimpanan material bahan, produksi, sampai pengemasan yang hingga pada akhirnya obat sampai dipasarkan dan dapat dikonsumsi oleh konsumen. Obat yang telah dipasarkan merupakan obat yang benarbenar telah terseleksi dan memenuhi syarat CPOB.

Salah satu proses yang terkait didalamnya adalah proses pengemasan primer atau proses penyetripan kaplet yang dilakukan menggunakan mesin yang sesuai dengan jenis kapletnya. Dalam industri farmasi proses pengemasan primer atau proses penyetripan kaplet dilakukan menggunakan mesin yang sesuai dengan jenis kapletnya. 7 tools adalah alat-alat bantu yang bermanfaat untuk menetapkan lingkup persoalan, menyusun data dalam diagramdiagram agar lebih mudah untuk dipahami, menelusuri berbagai kemungkinan penyebab persoalan dan memperjelas kenyataan atau fenomena yang otentik dalam suatu persoalan.

7 tools atau 7 QC (Quality Control) tools banyak dikenal luas dalam lingkup masyarakat pengendali mutu khususnya pada lingkup industri. Hal ini tidak dapat dipungkiri karena memang alat-alat bantu ini berkembang penggunaannya didalam proses kegiatan peningkatan mutu atau pemecahan masalah yang biasa dilakukan dalam konteks quality control circle atau quality improvement team, dan lain sebagainya.

Keberhasilan dalam menggunakan 7 tools sangat dipengaruhi oleh seberapa besar pengetahuan si pengguna alat-alat bantu ini. Semakin baik pengetahuan yang dimiliki, akan semakin tepat dalam memilih alat bantu yang akan digunakan. Itulah sebabnya ada 2 hal pokok yang perlu menjadi pedoman sebelum menggunakan 7 tools, yaitu: Efisien (tepat), Efektif (benar). Efisien maksudnya adalah ketepatan dalam memilih alat bantu yang sesuai dengan karakteristik yang akan dibahas, sedangkan Efektif artinya bahwa penggunaan alat bantu tersebut dilakukan dengan benar, sehingga persoalan menjadi lebih jelas, mudah dimengerti, dan memberikan peluang untuk diperbaiki. Tetapi, masalah-masalah pada mesin yang dapat menghambat kelancaran proses produksi akan terjadi. Oleh karena itu, penelitian ini untuk mencari solusi-solusi yang tepat agar masalah yang timbul dan menghambat kelancaran proses produksi mampu dikurangi, dengan tujuan untuk meningkatkan produktifitas mesin, mengurangi reject pada mesin stripping, meningkatkan tingkat keselamatan kerja operator, dan meningkatkan efisiensi dalam proses produksi.

\section{METODOLOGI}

\section{Identifikasi Masalah}

Dari hasil observasi (GEMBA) yang dilakukan di salah satu plant oleh para teknisi khususnya devisi maintenance pada mesinmesin yang digunakan pada plant tersebut, maka didapat beberapa masalah yang sering terjadi pada mesin-mesin tersebut.

Berdasarkan permasalahan di atas dilakukan pembobotan dengan mempertimbangkan aspek-aspek: Tingkat kejadian, Biaya / cost, dan Tingkat kemudahan.

\section{Pemilihan Masalah}

Setelah semua permasalahan telah teridentifikasi, maka permasalahan yang akan menjadi prioritas terlebih dahulu untuk dilakukan sebuah improvement, disini dapat menggunakan tool pareto untuk menentukan prioritas utamanya.

\section{Menentukan Fakta dan Data Awal}

Berikut ini adalah data penggukuran tingkat kebisingan guntingan pada mesin Strip untuk periode April - Juli 2014.

\section{Target}

Setelah didapat data dari data-data tingkat kebisingan di mesin Strip, maka diketahui bahwa tingkat kebisingan di mesin ini sudah melewati batas ambang normal pendengaran manusia. 
Analisa Kondisi yang Ada

Untuk mengetahui kondisi permasalahan lebih dalam, dilakukan analisa dengan membandingkan kondisi yang seharusnya (What Should Be Happen / WSBH) dengan kondisi yang ada (What Actualy Happen / WAH), dengan mempertimbangkan aspek-aspek Man, Methode, Machine, dan Material.

\section{Analisa Sebab Akibat}

Pada langkah ini digunakan tools diagram tulang ikan atau fishbone. Tools ini sangat bermanfaat untuk melihat faktorfaktor penyebab masalah untuk mencari akar masalahnya (root cause).

\section{HASIL DAN PEMBAHASAN}

\section{Identifikasi Masalah}

Berdasarkan data yang didapat, masalah-masalah tersebut antara lain :

1. Sistem pelumasan roller atas tidak lancer pada mesin cetak BB 4 B1.

2. Suara guntingan bising pada mesin stripping.

3. Supply steam pada mesin coating Sejong SFC-130 tidak stabil.

4. Guntingan tumpul pada mesin stripping HS 8 R A.

Dari permasalahan-permasalahan yang ada di atas dilakukan pembobotan dengan mempertimbangkan aspek-aspek: Tingkat kejadian, Biaya / cost, dan Tingkat kemudahan. Seperti terlihat pada tabel 1 .

Tabel 1 Penilaian masalah di plant NBL (Non Betalaktam)

\begin{tabular}{|c|c|c|c|c|c|}
\hline No & Masalah & $\begin{array}{l}\text { Tingkat } \\
\text { Kejadian }\end{array}$ & Cost & Kemudahan & Jumlah \\
\hline 1 & $\begin{array}{c}\text { Sistem pelumasan } \\
\text { roller atas tidak } \\
\text { lancar di mesin BB } \\
\text { 4 B I. }\end{array}$ & 1 & 2 & 2 & 5 \\
\hline 2 & $\begin{array}{l}\text { Suara guntingan } \\
\text { bising di mesin } \\
\text { strip }\end{array}$ & 3 & 3 & 3 & 9 \\
\hline 3 & $\begin{array}{l}\text { Supply steam } \\
\text { Sejong Coating SFC. } \\
130 \text { bermasalah. }\end{array}$ & 2 & 2 & 2 & 6 \\
\hline 4 & $\begin{array}{l}\text { Guntingan tumpul } \\
\text { di mesin HS } 8 \text { R A. }\end{array}$ & 2 & 3 & 2 & 7 \\
\hline
\end{tabular}

Keterangan kriteria penilaian menurut:

- Tingkat kejadian: 1. Jarang

2. Sedang

3. Sering

- Biaya (Cost):

$$
\begin{aligned}
& \text { 1. }>5.000 .000,-\rightarrow \text { Mahal } \\
& \text { 2. } 1.000 .000,-<5.000 .000,-\rightarrow \text { Sedang } \\
& \text { 3. }<1.000 .000,-\rightarrow \text { Murah } \\
& \text { 2. Sedang } \\
& \text { 3. Mudah }
\end{aligned}
$$

Dari empat permasalahan yang ada diatas, dilakukan pembobotan lagi dengan mempertimbangkan pengaruh dan keterkaitan tiap-tiap masalah terhadap aspek-aspek QCDSMPE (Quality, Cost, Delivery, Safety, Morale, Productivity, Environtment). Untuk itu kita prioritaskan

\begin{tabular}{|c|c|c|c|c|c|c|c|c|c|}
\hline No & Masalah & Q & C & D & $S$ & $M$ & $P$ & $E$ & Jumlah \\
\hline 1 & $\begin{array}{l}\text { Suara guntingan } \\
\text { bising di mesin } \\
\text { strip. }\end{array}$ & $Y$ & $Y$ & $Y$ & $Y$ & $Y$ & $Y$ & $Y$ & 7 \\
\hline 2 & $\begin{array}{c}\text { Supply steam } \\
\text { Sejong Coating } \\
\text { SFC-130 } \\
\text { bermasalah. }\end{array}$ & $Y$ & $Y$ & $Y$ & $\mathrm{~N}$ & $\mathrm{~N}$ & $Y$ & $\mathrm{~N}$ & 4 \\
\hline 3 & $\begin{array}{l}\text { Guntingan tumpul } \\
\text { di mesin HS } 8 \text { R A. }\end{array}$ & $Y$ & $Y$ & $Y$ & $\mathrm{~N}$ & $\mathrm{~N}$ & $Y$ & $\mathrm{~N}$ & 4 \\
\hline
\end{tabular}
(Stratifikasi) terlebih dahulu dengan membobotkan masalah-masalah tersebut berdasarkan aspek di atas. Seperti terlihat pada tabel 2 .

Tabel 2 Stratifikasi pengelompokan masalah

Keterangan : $\mathrm{Y}$ : Mempunyai pengaruh. $\mathrm{N}$ : Tidak Berpengaruh.

Keterangan nilai-nilai yang mempunyai pengaruh terhadap tiap-tiap masalah:

1. Suara guntingan bising bising di mesin Strip

a. Quality

Diperkirakan bahwa suara bising yang ditimbulkan oleh mesin Strip diakibatkan karena adanya penurunan kualitas yang dialami oleh part yang ada dimesin tersebut. Dan karna hal tersebut, maka sistem yang bekerja didalam mesin tersebut ada yang kurang sempurna atau sudah tidak bekerja dengan semestinya. 
b. Cost

Jika terjadi kerusakan pada part yang ada pada mesin strip ini, maka cost yang dibutuhkan untuk repair maupun penggantian part yang rusak tersebut akan tinggi.

\section{c. Delivery}

Karena masih terkait dalam sistem line produksi, maka bila terjadi suatu masalah pada mesin strip, dapat dipastikan bahwa sistem yang berada setelahnya terganggu.

\section{d. Safety}

Dari segi keamanan dapat disimpulkan bahwa permasalahan yang terjadi di mesin strip ini dapat membahayakan si operator. Karena apabila suara bising yang ditimbulkan itu berasal dari part-part yang bersentuhan, maka di khawatirkan terjadi suatu benturan keras yang dapat mengakibatkan pecah dan terpentalnya part yang bersentuhan tersebut. Selain itu suara bising yang ditimbulkan oleh mesin strip ini menjadi salah satu polusi yang lamakelamaan dapat menggangu pendengaran si operator.

\section{e. Morale}

Apabila masalah ini tidak cepat ditanggulangi, maka kondisi si operator dari segi konsentrasi, dan kenyamanan bekerjanya dapat terganggu. Selain itu teknisi juga selalu dituntut untuk terus fokus pada penanganan masalah yang ada di mesin strip ini hingga selesai.

\section{f. Productivity}

Karena dapat mempengaruhi moral operator, maka disimpulkan bahwa hasil atau output dari mesin strip ini pun menjadi tidak maksimal.

\section{g. Environment}

Jika terjadi kegagalan produksi yaitu terdapat material pollycel dan obat yang harus dibuang, dan apabila pada saat pemusnahannya harus dibakar membuat polusi udara dan berdampak buruk pada lingkungan sekitar. Seperti sudah diketahui, masalah yang terjadi di mesin kunglong ini dapat menggangu ruangan-ruangan yang ada disekitar ruangan mesin kunglong tersebut, akibat dari polusi udara yang ditimbulkan dari mesin ketika pintu ruangan mesin ini dibuka ataupun terbuka.

\section{Supply steam SEJONG COATING SFC-130} bermasalah.

a. Cost

Dari sudut pandang cost berpengaruh karna apabila supply steam mengalami ketidakstabilan, maka produk yang akan di coating (granul) dapat mengalami kerusakan. Dan apabila hal ini terjadi maka, kerugian pada cost produksi untuk produk yang rusak ini sangat besar.

b. Delivery

Dari segi delivery yang dipengaruhi adalah system line produksi dari mesin SEJONG SFC-130 ini.

c. Morale

Apabila produk yang di coating mengalami kerusakan, maka operator akan ditegur oleh atasannya, dan dapat dianggap lalai dalam mengoprasikan mesin.

\section{d. Productivity}

Apabila dalam proses coating supply steam mengalami masalah maka dapat mengakibatkan kerusakan pada produk yang sedang di coating.

3. Guntingan tumpul di mesin stripping HS 8 $\mathrm{RA}$

a. Quality

Apabila guntingan atau pisau guntingan mesin HS 8 tumpul, maka kualitas dari pisau atau guntingan tersebut otomatis menurun sehingga mengakibatkan fungsi dari pisau atau guntingan tersebut juga mangalami penurunan.

b. Cost

Untuk repair maupun penggantian pisau atau guntingan mesin HS 8 dibutuhkan biaya yang besar.

c. Delivery

Karna mengunakan system line produksi, maka system yang berada setelahnya terganggu. 


\section{d. Productivity}

Hasil atau output dari mesin ini sudah pasti tidak maksimal, dikarenakan pisau atau guntingan sudah mengalami penurunan kualitas fungsi.

\section{Pemilihan Masalah}

Setelah semua permasalahan telah teridentifikasi, maka permasalahan yang akan menjadi prioritas terlebih dahulu untuk dilakukan sebuah improvement, disini dapat menggunakan tool pareto untuk menentukan prioritas utamanya. Seperti terlihat pada tabel 3.

Tabel 3 Lembar data untuk pembuatan diagram Pareto

\begin{tabular}{|c|c|c|c|c|c|}
\hline No & Permasalahan & $\begin{array}{c}\text { Jumlah } \\
\text { Kasus }\end{array}$ & $\begin{array}{c}\text { Kumulative } \\
\text { Total }\end{array}$ & $\begin{array}{c}\text { Persen } \\
(\%)\end{array}$ & $\begin{array}{l}\text { Kumulative } \\
\text { Persen (\%) }\end{array}$ \\
\hline 1 & $\begin{array}{l}\text { Suara guntingan } \\
\text { bising di mesin } \\
\text { strip. }\end{array}$ & 7 & 7 & 47 & 47 \\
\hline 2 & $\begin{array}{c}\text { Supply steam } \\
\text { Sejong Coating } \\
\text { SFC-130 } \\
\text { bermasalah. }\end{array}$ & 4 & 11 & 27 & 73 \\
\hline 3 & $\begin{array}{l}\text { Guntingan } \\
\text { tumpul di mesin } \\
\text { HS \& R A. }\end{array}$ & 4 & 15 & 27 & 100 \\
\hline Total & 15 & & $100 \%$ & & \\
\hline
\end{tabular}

Untuk permasalahan pertama terdapat tujuh kasus dengan persen sebanyak $47 \%$. Pada permasalahan kedua terdapat dua kasus dengan persen sebanyak $27 \%$. Sedangkan pada permasalahan ketiga terdapat empat buah kasus dengan persen sebanyak 27\% dengan prinsip diagram Pareto, bahwa akar permasalahan yang sedikit namun memiliki persentase masalah yang paling besar, ada pada permasalahn ketiga, yaitu "gunting yang tumpul di mesin HS \& RA."

Berikut gambar 1 memperlihatkan diagram pareto yang menggambarkan prioritas pombobotan masalah berdasarkan tabel 3 yang telah dibuat sebelumnya. Dapat dilihat pada sumbu " $x$ " mewakili permasalahan yang ada pada kasus ini. Sumbu "y" yang pertama sisi kiri grafik, mewakili jumlah kasus yang ada pada tiap permasalahan yang timbul. Sedangkan pada sumbu "y "yang ke dua, mewakili persentse kumulatif dari prinsip diagram Pareto.

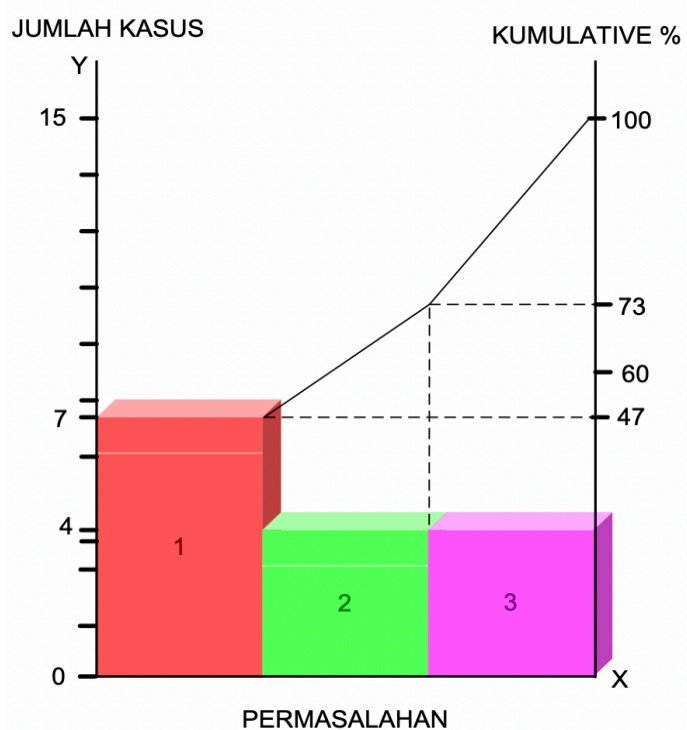

Gambar 1 Diagram Pareto pembobotan masalah

Berdasarkan hasil pembobotan di atas, maka ditentukan bahwa masalah yang akan diangkat dan dilakukan improvement adalah "Suara guntingan bising di mesin Strip".

\section{Menentukan Target}

Setelah didapat data dari data-data tingkat kebisingan di mesin Strip, maka diketahui bahwa tingkat kebisingan di mesin ini sudah melewati batas ambang normal pendengaran manusia, seperti terlihat pada gambar 2.

Oleh karena itu ditentukan target yang akan dicapai adalah sebagai berikut : Menurunkan nilai Decibel (tingkat kebisingan) pada guntingan mesin Strip dari rata-rata $94.29 \mathrm{~dB}$ menjadi $80 \mathrm{Db}$. Mencapai target pada point pertama dalam waktu 5 bulan.

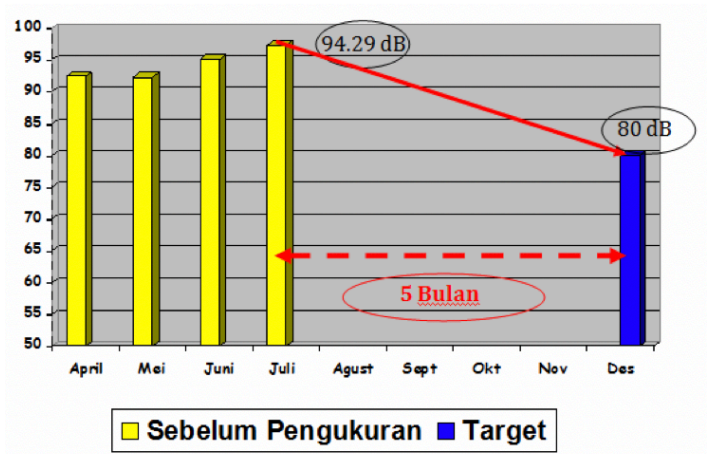

Gambar 2 Diagram target menurunkan tingkat kebisingan 


\section{Analisa Kondisi yang Ada}

Untuk hasil kondisi permasalahan, dilakukan analisa dengan mem-bandingkan kondisi yang seharusnya (What Should Be Happe (WSBH) dengan kondisi yang ada (What Actualy Happen/WAH), dengan mempertimbangkan aspek-aspek Man, Methode, Machine, dan Material.

\section{Analisa Sebab Akibat}

Pada langkah ini digunakan tools diagram tulang ikan atau fishbone. Tools ini sangat bermanfaat untuk melihat faktorfaktor penyebab masalah untuk mencari akar masalahnya (root cause). Seperti terlihat pada gambar 3 merupakan diagram fishbone Secara keseluruhan, sedangkan gambar 4, 5, 6 dan 7 merupakan akar masalah tiap metode, yaitu: man, machine, material dan method. Dalam penelitian ini tidak membahas tentang faktor measurement dan environment yang mungkin mempengaruhi kebisingan mesin strip obat.

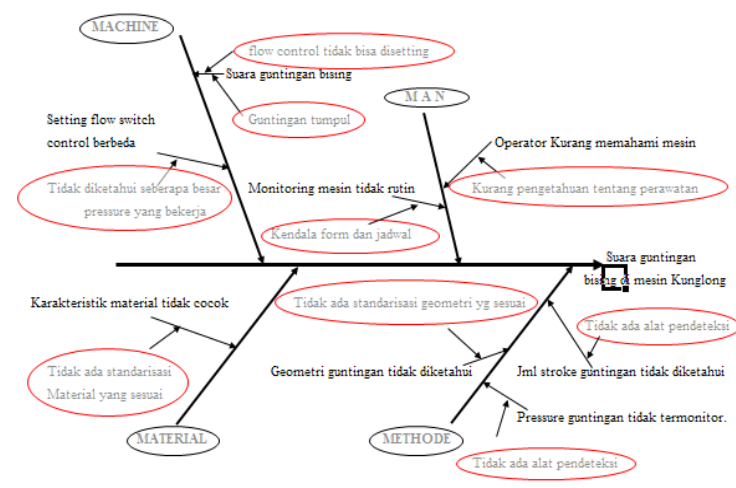

Gambar 3 Diagram tulang ikan keseluruhan

Berikut akan dijelaskan akar masalah dari tiap-tiap faktor penyebab suara gunting yang bising pada mesin Kunglong yang digunakan dalam proses produksi pengemasan strip obat.

Pada gambar 4, diperlihatkan faktor dari man (orang/operator). Faktor dari orang/operator memiliki dua masalah utama, yaitu: operator kurang memahami mesin dan operator tidak rutin memonitoring mesin. Untuk masalah utama "operator kurang memahami mesin", setelah dilakukan observasi dihasilkan masalah sekunder terhadap masalah utama tersebut yaitu "kurangnya pengetahuan operator tentang perawatan mesin".

Sedangkan pada masalah utama "operator tidak rutin memonitoring mesin", memiliki masalah sekunder, yaitu "kendala form dan jadwal" setelah dilakukan observasi hal tersebut terjadi akibat tidak buatnya jadwal rutin monitoring mesin strip obat.

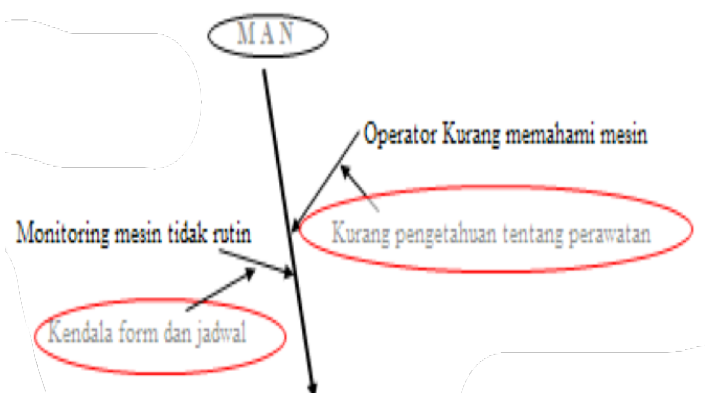

Gambar 4 Faktor man (orang/operator)

Gambar 5, faktor dari machine (mesin) memiliki dua masalah utama, yaitu: suara gunting yang bising dan setingan flow switch control yang berbeda. Pada masalah utama "suara gunting yang bising", dari observasi menghasilkan dua masalah sekunder terhadap masalah utama tersebut yaitu "gunting yang tumpul" dan "flow control tidak bisa di seting".

Untuk masalah utama yang kedua, yaitu "setingan flow switch control yang berbeda", memiliki masalah sekunder, yaitu "tidak diketahui seberapa besar preassure yang bekerja".

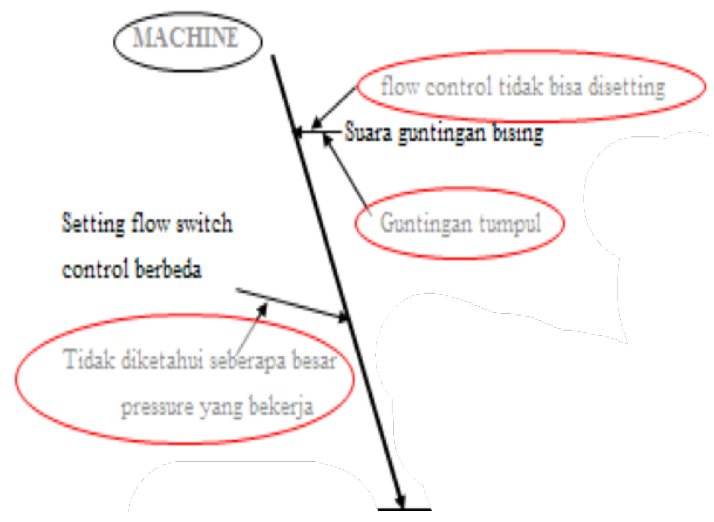

Gambar 5 Faktor machine (mesin)

Gambar 6, menyajikan gabar dari bagian fishbone diagram dari faktor material yang memiliki satu masalah utama, yaitu: karakteristik material yang tidak cocok. Pada masalah utama tersebut, dari observasi menghasilkan satu masalah sekunder, yaitu "tidak adanya standarisasi material yang sesuai". Hal tersebut bisa terjadi akibat penggunaan mesin import yang berbeda iklim di negara asal pembuatnya, sehingga material dapat terdeformasi akibat lingkungan atau lebih tepatnya pengaruh iklim tropis di negara Indonesia. 


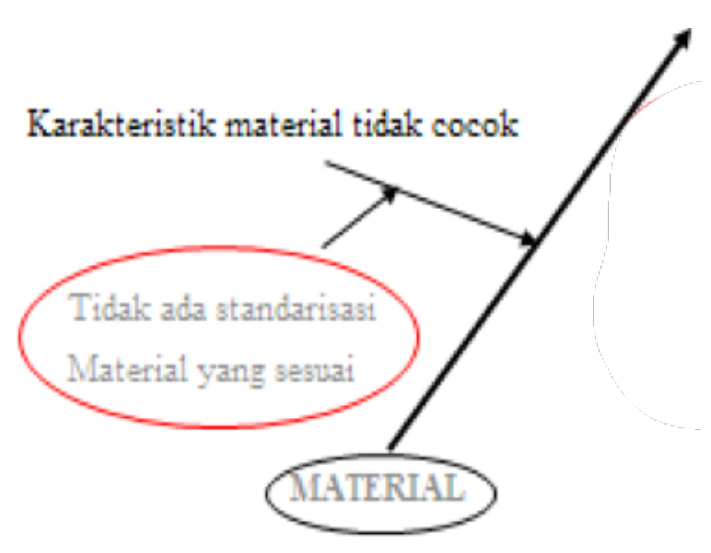

Gambar 6 Faktor material

Pada gambar 7, ditampilkan akar masalah faktor dari method (cara penggunaan/metode). Faktor dari method (cara penggunaan/metode) memiliki tiga masalah utama, yaitu: geometri gunting tidak diketahui, jumlah stoke gunting tidak diketahui dan preasure gunting tidak termonitor. Untuk masalah utama "geometri gunting tidak diketahui", setelah dilakukan observasi dihasilkan masalah sekunder terhadap masalah utama tersebut yaitu "tidak ada standarisasi geometri yang sesuai".

Sedangkan pada masalah utama "jumlah stoke gunting tidak diketahui", memiliki masalah sekunder, yaitu "tidak alat pendeteksi". Untuk masalah sekunder yang ketiga, yaitu preasure gunting tidak termonitor, memiliki masalah sekunder "tidak adanya alat pendeteksi". Dalam faktor ini terdapat dua masalah sekunder yang sama, yaitu; "tidak adanya alat pendeteksi"

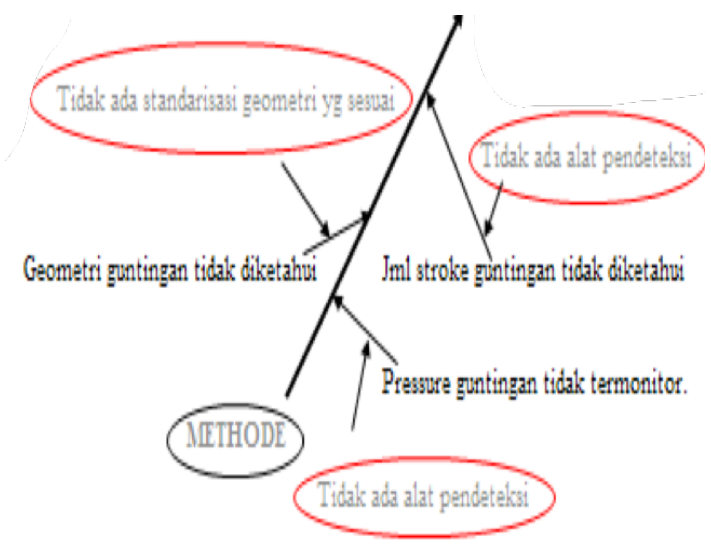

Gambar 7 Faktor method (cara penggunaan/metode)

Berdasarkan analisa sebab akibat dengan menggunakan diagram Fishbone, secara keseluruhan ditemukan 9 hal yang menjadi akar penyebab kebisingan pada guntingan mesin Strip, yaitu:

1. Kurang pengetahuan perawatan bagi operator.

2. Kendala pada form dan jadwal untuk memonitoring.

3. Pressure guntingan tidak diketahui.

4. Jumlah stroke guntingan tidak diketahui.

5. Tidak ada standard geometri guntingan.

6. Tidak diketahui seberapa besar pressure yang bekerja.

7. Guntingan tumpul.

8. Tidak ada standard material yang sesuai.

9. Flow switch control tidak bisa di setting.

Adapun saran tindakan untuk mengatasi akar penyebab kebisingan pada guntingan mesin Strip diantaranya, yaitu:

1. Memberikan pelatihan kepada operator tentang perawatan pada mesin yang digunakan dalam proses produksi, khususnya mesin gunting strip obat.

2. Dilakukan kontrol pengisian form serta jadwal monitoring mesin.

3. Menghitung atau mengukur preasure gunting yang terjadi sebagai parameter seting flow switch.

4. Menghitung jumlah stoke pada gunting sebagai acuan parameter setup mesin.

5. Dilakukan pengukuran untuk menentukan geometri minimal dan. maksimal gunting.

6. Melakukan pengecekan rutin serta menentukan standar minimal dan maksimal ketumpulan mata gunting untuk menentukan waktu penggantian mata gunting.

7. Melakukan analisis material gunting agar diketahui jenis material yang tepat untuk kondisi iklim di Indonesia.

\section{SIMPULAN}

Dari penelitian ini, dapat disimpulkan pada aspek berikut :

1. Aspek Teknis

- Standarisasi setingan mesin terhadap produk yang diproses pada mesin sehingga memudahkan operator dalam melakukan persiapan.

- Optimalisasi output dengan meminimalkan reject produk. 
- Diperoleh waktu proses yang optimal, sehingga meminimasi proses setting pada pertengahan proses produksi.

- Rasa nyaman bagi operator dalam mengoperasikan mesin.

2. Aspek Ekonomis

- Mengurangi biaya re-work

- Meminimalisasi kemungkinan timbulnya biaya medis yang dapat terjadi pada operator.

\section{DAFTAR PUSTAKA}

Gaspersz Vincent, Statistical Process Control, Jakarta : Yayasan Indonesia Emas Dan Institut VINCENT, 1998.

Grant Eugene L. dan Richard S. Leavenworth, Statistikal Quality Control, 6 Th Edition, New York: McGraw-Hill Book Company, 1988.

Ishikawa Kaoru, Teknik Penuntun Pengendalian Mutu, Cetakan ke 3 Penerjemah Nawolo Widodo, Jakarta : PT. Mediyatama Sarana Perkasa, 1988.

Kunglong Machinery, Operation Manual for Automatic Strip Packaging Machine Model SP - 180, Jakarta : PT. Imas Asri Mulia, 2003. 